\title{
Development of Regional Planning Criteria for Health Services in the City of Riyadh
}

\author{
Suleiman S. Abu-Kharmeh ${ }^{1}$ \\ ${ }^{1}$ Faculty of Planning and Management, Balqa Applied University, Jordan \\ Correspondence: Suleiman S. Abu-Kharmeh, Faculty of Planning and Management, Balqa Applied University, \\ Jordan. Tel: 962-795-592-761. E-mail: dr_kharmeh@yahoo.com
}

Received: March 26, 2012 Accepted: April 24, 2012 Online Published: May 30, 2012

doi:10.5539/jsd.v5n6p124

URL: http://dx.doi.org/10.5539/jsd.v5n6p124

\begin{abstract}
This study aimed at developing criteria for planning health services in the city of Riyadh through assessing the actual distribution of these services and comparing them with planning criteria adopted by the Municipality of Riyadh, local, Arab and foreign cities, in order to propose planning criteria that best serve citizens of Riyadh city more fairly and efficiently. Data related to health services and their attributes were gathered and incorporated into a GIS database. The results of the study showed regarding the primary health centers that the criterion of the service's coverage rate of the Riyadh Municipality was slightly applied, notwithstanding the criterion of the served population was moderately applied, the criterion of the square meters of land per capita was slightly applied, the criterion of the served population was asymptotic to that one in Dubai. The criterion of the land's area allocated to per capita was relatively high in comparison with other cities. While the results regarding hospitals showed that the criterion of the service's coverage rate for the municipality was moderately applied, the criterion of the served population was asymptotic to that one in Dubai and the criterion of the land's area allocated to per capita was relatively high in comparison with other cities.
\end{abstract}

Keywords: regional planning, planning criteria, health services, location, development

\section{Introduction}

The provision of public services in general and especially health ones are necessary to save human's life and secure their welfare. It must be provided to citizens based on the principles and criteria of public interest without bias to a particular place. The provision aims to secure a sustainable standard of living for all citizens, manage and develop these services optimally (Ministry of Planning, 2004).

Although the provision of health services is non-profit, it does not imply that they don't have economic and social returns since investment in health is considered for developing the human resources at the level of society as a whole and pays off in the long term. This requires the attention to the optimal allocation of all the input elements to satisfy the needs of the community at the highest degree of efficiency. Accordingly, the services related to satisfying the basic needs of the population and delivery of services is primarily the responsibility of the state as it represents the pillars of its sovereignty. The efficient management of public utilities is required for the proper utilization of resources allocated to them (Ministry of Health, 2002).

To raise and improve the services provided to the population, it is necessary existing a set of planning criteria which helping to provide these services based on comprehensiveness and justice.

These criteria represent a support tool for decision makers in the field of services, and also contributes to estimate the extent of adequacy for the levels of availability of these services in comparison with the population needs according to the region and population categories, attaining coordinative plans for providing public services in the future in order to overcome obstacles, and meet the anticipated needs in the future according to the future population projections in 2023 (Ministry of Municipal and rural Affairs, 2001).

Therefore, this study is to develop planning criteria for of health services in the city of Riyadh through the assessment of actual reality and compared them with planning criteria approved in the Municipality of Riyadh. In addition, to compare them with planning criteria in the other local, Arab and foreign cities in order to propose planning criteria that may contribute in the development of health services provided to the citizens in city of Riyadh and distributed them fairly and efficiently. 


\section{Study Objectives}

The study seeks to achieve a set of goals as follows:

(1) Study the current situation of health services in Riyadh city.

(2) Investigate the compliance of the current distribution of health services with approved planning criteria for Riyadh city.

(3) Explore the international practices in terms of planning criteria for health services.

(4) Suggest criteria which go in line with the architect fabric of Riyadh city.

\section{Methodology of Developing the Planning Criteria}

Development of planning criteria is based on a number of considerations as follows (OECD, 2008):

(1) Population data according to their geographical distribution, demographic characteristics, sex and age categories.

(2) The levels of different population categories interested in health services. These levels are affected by social and economic development and also by trends of sectorial policies.

(3) Technical and procedural considerations committed by those responsible for health services apart from the availability of autonomous demand by population in regular circumstances.

(4) Sectorial criteria that take into account the rates of autonomous turnout on health services from one hand, and technical considerations which are committed by the responsible departments on the other hand for using it in estimating the needs of the population for the health services, and thus measuring the deficit or surplus of demand through comparing the estimated demand with the available supply.

The planning criteria in the various cities of the world include all or some of the following categories (Charnes et al., 1995):

(1) Criteria deals with the extent of covering service units and is expressed through the service coverage rate, the number of beneficiaries, and the number of population covered by the service.

(2) Criteria relates to the provision of necessary plots for the units of service that specify the conditions of land divisions, expropriation and management of land owned by government entities. It is expressed in one of the following indicators: the number of square meters per beneficiary and the number of square meters per capita in the coverage area.

(3) Criteria related to the size of construction which includes the service unit that determine the built-up area and is expressed by: number of square meters of the facility, the number of meters per beneficiary and the number of square meters per capita of the population.

(4) Criteria relates to equipping and operating the service unit: which specifies conditions for providing health services such as: the availability of special equipment (laboratories, toilets, etc.), identifying areas dedicated to specific parts of the facility (clinics sizes, parking sizes, etc.) and different technical conditions (altitudes, the conditions for public safety, etc.).

These criteria vary depending on its nature, for example, the first category of the criteria reflects the coverage policy, while the second category related to the responsibilities of urban planning, the third category of the criteria related to the engineering considerations, while the fourth related to the operating and quality conditions. These criteria integrate with each other and are difficult to separate them most probably because they are not independent from each other (For example: the size of the building is linked to the breadth of land and building size governs the possibility of providing equipment and operational requirements). Because some of these criteria are linked indirectly to underlying considerations such as population density resulting from the pattern of urban practice and the single size for each of the service units. For example, relying on a certain range of service in an area has certain density results underlying identifying of the number of population served by the facility. It is well known that the economic cost for operating any service facility depends largely on its size and the number of beneficiaries. Therefore, the adoption of limited coverage service in a low density region leads to small size service units and high cost (OECD, 2008). 


\section{Considerations for the Use of Planning Criteria}

The planning criteria are related with three basic considerations (Ministry of Municipal and rural Affairs, 2000):

(1) Availability of lands, which is in turn affected by the planning legislations and processes of expropriation. The more available lands to receive health services due to the presence of urban planning systems and regulations in place, the more easily to meet the demand and upgrade the level of service.

(2) The demand for health services is influenced by population density and transportation. As the population density is increased and mobility become accessible through, the provision of lands, meeting demand and improving the level of service will be easier.

(3) The level of health service is influenced by shortness of distances crossed, providing sufficient spaces. The more flexibility adopted in determining the level of service in terms of geographical coverage and relying on public transport instead of walking or the use of private cars, or in terms of space required for each facility as a result for merging similar facilities (health centers and hospitals) in unified sites and shared in using equipments that require large areas, the less pressure on lands and the more easier to meet the demand.

In order to make criteria realistic and feasible, planners must take into account the balance between such considerations. For the city of Riyadh, the following can be observed (Ministry of Municipal and rural Affairs, 2000; Ministry of Health, 2007):

(1) Demand is characterized by low density and extended area of the city. From other side, it is possible to benefit from the size of the road network and the electrical train proposed to facilitate the transition within the city depending on more effective means of transport than the current reality governed by using private cars.

(2) Availability of lands in the city of Riyadh is characterized by distinguished features since the governmental lands are available in the outskirts of the city but rare in the city center. But the problem highlights in new neighborhoods surrounding the old center and built according to the hierarchical layout style and then changing took place in the use of governmental lands for many reasons, generating large deficit in the provision of public lands and the city began to suffer from its negative consequences seriously.

(3) Regarding the levels of service, the commitment to the geographical coverage of services is no longer viable in most neighborhoods without substantial modification in the land policy.

Therefore, the proposed criteria should take into account the lands problem and adapt the required levels of service within the area of giving priority to areas that suffer from deficits in the availability of public services.

\section{Data Collection}

Data compiled from official sources showed the following characteristics:

- Services without spatial coordinates and without descriptive information.

- Services with available spatial coordinates, but without service descriptive information.

- $\quad$ Services without spatial coordinates, but with available service descriptive information.

- Information and various statistics (urban, demographic, social, ...).

Data was collected, indexed, classified and integrated into GIS database. For this reason and to obtain the missing data, a questionnaire has been designed according to the types, and categories of health services (Bandura, 2006).

\section{The Geographical Scope of the Field Survey}

The field survey and cadastral boundaries which was conducted by Al-Riyadh Development Authority (ADA) covers the borders of the urban development area of the city of Riyadh (till the year 2028) with a total area of about 5400 square kilometers. 


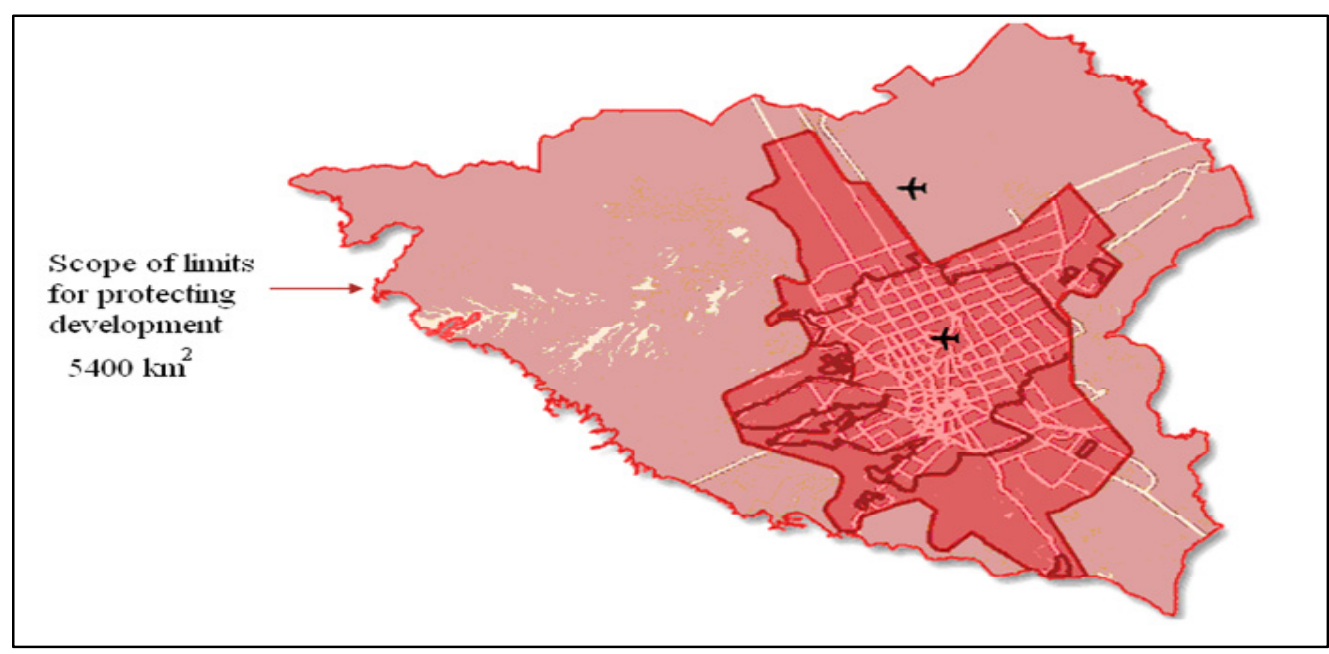

Figure 1. The boundaries of the geographical coverage of the field survey

\section{Produce Maps of the Geographic Sectors}

A basic map was provided by the ADA for the usage of the field surveys, the map shows the borders of sub-municipalities, Districts, sub-districts, and blocks which is divided into Parcels and buildings, each has a serial code number to be identified in the questionnaire. A randomized verification of the findings of the survey was conducted through satellite images of modern and high-resolution (Quick Bird) with accuracy up to $60 \mathrm{~cm}$.

\section{Field Survey Work}

The survey questionnaires were filled in the following ways:

- Visiting the health service site: the service site was visited and interviewed the person in charge and filled the questionnaire according to the information given by supported documents or references.

- Phone call: In cases where field researchers encountered obstacles which prevented them from accessing the facility, phone calls were used to get the required information.

\section{Results}

The investigated health facilities included are: primary care centers, public specialized and general hospitals that provide health services for residents. The results of the analysis showed:

\section{A) Primary health care centers}

They are the essence of medical services because they provide primary health care services at the level of neighborhoods and residential zones. They establish personal health files for all families within the coverage area of service for treatment and transfer to specialized medical centers if necessary. The center includes rooms for examination, waiting halls for male and female patients, and an emergency room. It may contain a laboratory, pharmacy and ambulance unit attached with services such as toilets, stockroom and maternity-infancy care offices (Ministry of Health, 2000).

\section{B) Hospitals}

It is divided into two types: General and specialized hospitals:

General hospitals: provide the basic level of health services. It involve the most medical specialties including sections of different specializations and rooms for surgery with its accessories, laboratories, workshops for medical analysis and X-ray, sections for reception and emergency, ambulance unit, admission, and facilities for services such as kitchens to prepare food, rooms for physicians and nurses, administrative and service appendages, and others. It should be noted that the hospitals are a stand-alone projects that need an in-depth study of each case. The planning criteria to be proposed later in the study are considered to be a general indicator and should not be applied without detailed study for each site chosen during the distribution of demand needs.

Specialized hospitals: provide treatment and preventive services in a particular specialty (pediatrics, obstetrics, ophthalmology, psychiatry, thoracic). They cover health services at the range of the city and includes all equipment such as general hospital, the necessary medical departments and all the accessories according to the specialty of hospital (The Ministry of Health, 2000). 
Table 1. Summary of the current situation of health services in the city of Riyadh

\begin{tabular}{|c|c|c|c|c|c|c|c|c|c|}
\hline \multirow[b]{2}{*}{ Items } & \multicolumn{4}{|c|}{ Public } & \multicolumn{4}{|c|}{ Private } & \multirow[b]{2}{*}{ Total } \\
\hline & $\begin{array}{l}\text { General } \\
\text { Hospital }\end{array}$ & $\begin{array}{c}\text { Specialized } \\
\text { hospital }\end{array}$ & $\begin{array}{l}\text { Primary } \\
\text { care } \\
\text { center/ } \\
\text { clinic }\end{array}$ & Total & $\begin{array}{l}\text { General } \\
\text { hospital }\end{array}$ & $\begin{array}{c}\text { Specialized } \\
\text { hospital }\end{array}$ & $\begin{array}{l}\text { Primary } \\
\text { care } \\
\text { center/ } \\
\text { clinic }\end{array}$ & Total & \\
\hline Number & 15 & 10 & 65 & 90 & 24 & 2 & 205 & 231 & 321 \\
\hline No. Beds & 4977 & 4380 & 1177 & 10534 & 4989 & 292 & 2723 & 8004 & 18538 \\
\hline $\begin{array}{c}\text { No. } \\
\text { physicians }\end{array}$ & 1388 & 2598 & 645 & 4631 & 3022 & 200 & 2083 & 5305 & 9936 \\
\hline No. nurses & 4927 & 4325 & 1811 & 11063 & 8595 & 375 & 2812 & 11782 & 22845 \\
\hline $\begin{array}{l}\text { Occupancy } \\
\text { rate (note 1) }\end{array}$ & 1363 & 2250 & 12226 & 15839 & 1911 & 15 & 166 & 2092 & 17931 \\
\hline $\begin{array}{l}\text { No. owned } \\
\text { buildings }\end{array}$ & 10 & 10 & 32 & 52 & 16 & 2 & 51 & 69 & 121 \\
\hline $\begin{array}{l}\text { No. rented } \\
\text { buildings }\end{array}$ & 2 & - & 29 & 31 & 7 & - & 124 & 131 & 162 \\
\hline $\begin{array}{l}\text { Unknown } \\
\text { ownership }\end{array}$ & 3 & - & 4 & 7 & 1 & - & 30 & 31 & 38 \\
\hline
\end{tabular}

Table 2. Indicators of health services quality

\begin{tabular}{cccc}
\hline Sector & Bed/ health unit & $\begin{array}{c}\text { Patient/health unit } \\
\text { (note 2) }\end{array}$ & Physician/health unit \\
\hline Public & & & \\
Public hospital & 374 (note 3) & 452 & 173 \\
Preliminary Care & 18 & 260 & 10 \\
Private & & & 124 \\
Private hospital & 203 & 120 & 13 \\
Preliminary Care & 10 & 394 & \\
\hline
\end{tabular}

Table 3. Comparison of indicators of health services quality (public - private)

\begin{tabular}{cccccccc}
\hline $\begin{array}{c}\text { Comparison of } \\
\text { health indicators }\end{array}$ & $\begin{array}{c}\text { International } \\
\text { average (2007) }\end{array}$ & $\begin{array}{c}\text { International } \\
\text { average } \\
(1995-2003)\end{array}$ & $\begin{array}{c}\text { Ministry of } \\
\text { Health } \\
\text { Criteria }\end{array}$ & $\begin{array}{c}\text { Public } \\
\text { Health } \\
\text { services }\end{array}$ & $\begin{array}{c}\text { Private } \\
\text { Health } \\
\text { services }\end{array}$ & $\begin{array}{c}\text { Public \& } \\
\text { Private Health } \\
\text { services }\end{array}$ & USA \\
\hline $\begin{array}{c}\text { Hospital bed/ } \\
1000 \text { individual }\end{array}$ & 7.3 & 3.6 & 2.5 & 1.89 & 1.2 & 2 & 3.6 \\
$\begin{array}{c}\text { Physician/1000 } \\
\text { individual }\end{array}$ & 1.7 & 1.7 & - & 1 & 2.5 & 2.1 & 2.3 \\
\hline
\end{tabular}

\section{Comparison of Current Situation with the Criteria of the Municipality of Riyadh}

The current reality of health services was evaluated through comparison with the current criteria approved by the Municipality (Ministry of Municipal and rural Affairs, 2000) which include the coverage rate for both service units represented in the geographical coverage of the service (service coverage rate), and the number of people covered by the service. In addition to the criteria concerning the provision of plots required for each of the service units, ie the number of square meters per capita of served population. This was done through the graphs show the number of services that fall within or outside the criteria of Municipality and through maps showing the extent of compatibility for the current reality of these services with the criteria of Municipality. 
It required identifying the coverage of service for each service unit, compute the number of served population within it, and the coverage of its service in meters, in addition to its land area for the served population (Ebert \& Welsch, 2004). This was done through the use of geographic information systems (GIS) and the technology of Thiessen Polygon specifically which define polygonal (Polygon) service per unit of service in which the coverage of a service for each unit can be obtained as follows (Charnes et al., 1995):

(1) Calculating population per unit of service within the coverage of service that was specified in the Thiessen Polygon. Calculate the service scope rate per unit of service through the development of a mathematical equation in the GIS operates automatically and computing the average of distances from the unit of service to the units surrounding it.

(2) Calculating the land area of each unit of service for the served population within the Thiessen Polygon in order to extract the criterion of area land service per individual of population.

(3) Grouping units within specific ranges in order to compare them with the coverage of Municipality criteria. This information were then converted into an Excel file and included in moving tables (Pivotable) (Office of National Statistics, 2005) so as to check the compliance of the current status of these services with the criteria of Municipality. Then graphs were extracted showing the number of service units that fall within or outside the criteria of Municipality.

(4) Then graphs were converted into statistical circles (Pie charts) so as to obtain an accurate assessment (percentages) reflects the extent of compliance for the current service criteria with the criteria of the Municipality.

(5) Finally, the comparison results were included with the criteria of Municipality within illustrative maps at the sub-municipal level.

The following graphs and charts show comparing the results of analysis of the reality of these services with the criteria approved by the Municipality of Riyadh:

(A) Primary Health centers

These results show the following:

- The criterion of service coverage rate for the Municipality is applied slightly where the majority of clinics (94\%) have service coverage rate much wider of the criterion applied by the Municipality ( $800 \mathrm{~m})$.

- The criterion of served population is moderately applied where $74 \%$ of the clinics serving much more numbers of residents than what approved in the Municipality criterion (clinic per 8000 people).

- The criterion of square meters of land per person is applied slightly where $88 \%$ of clinics covering a square meter of land per capita less than the criterion of Municipality and only $4 \%$ falls within the criterion of the Municipality ( 0.34 to $0.48 \mathrm{~m}^{2} /$ people).

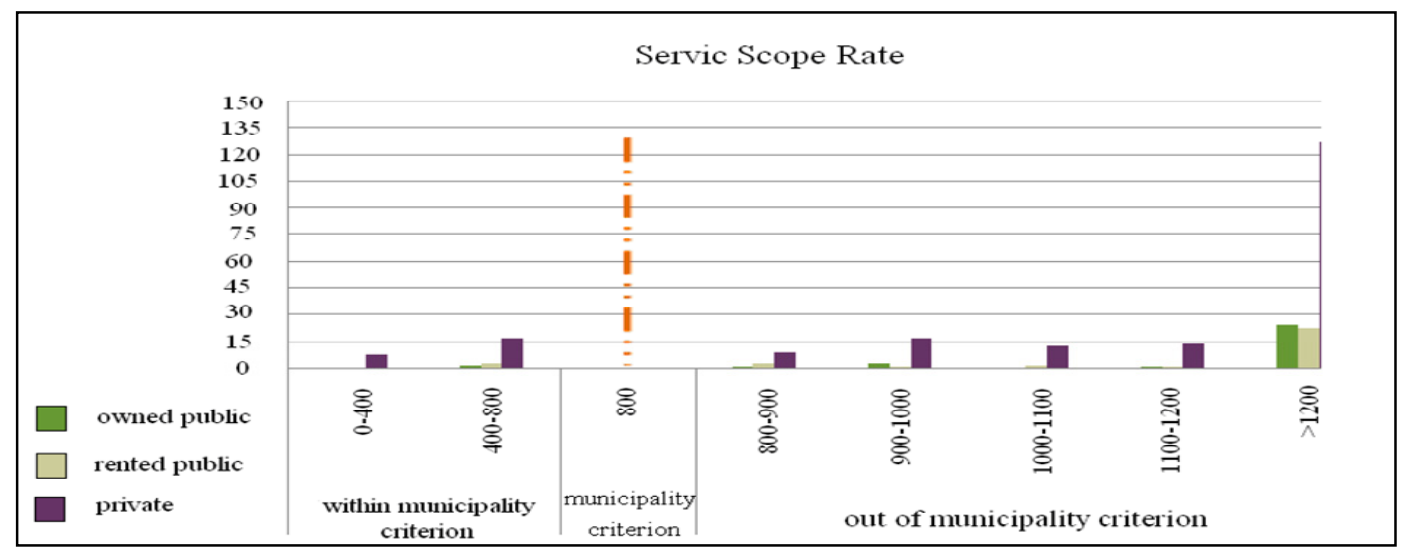

Figure 2. Primary health care centers (clinics) / service coverage rate (municipality criterion: $800 \mathrm{~m}$ ) 


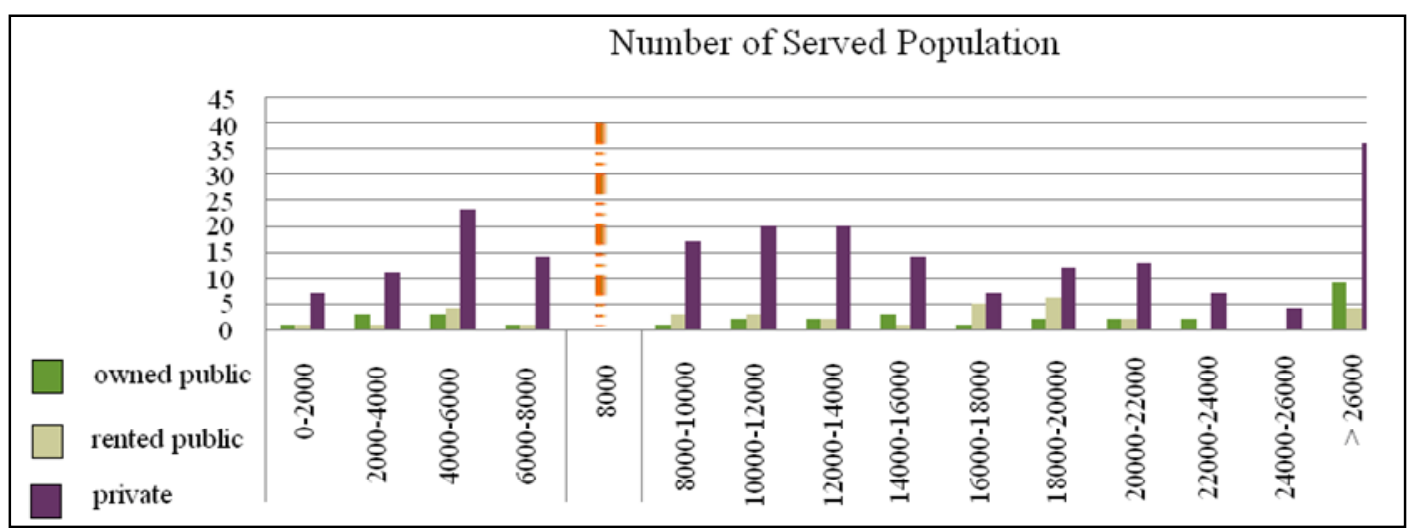

Figure 3. Preliminary care centers (clinics)/number of served population (Municipality criterion: clinic per $8,000)$

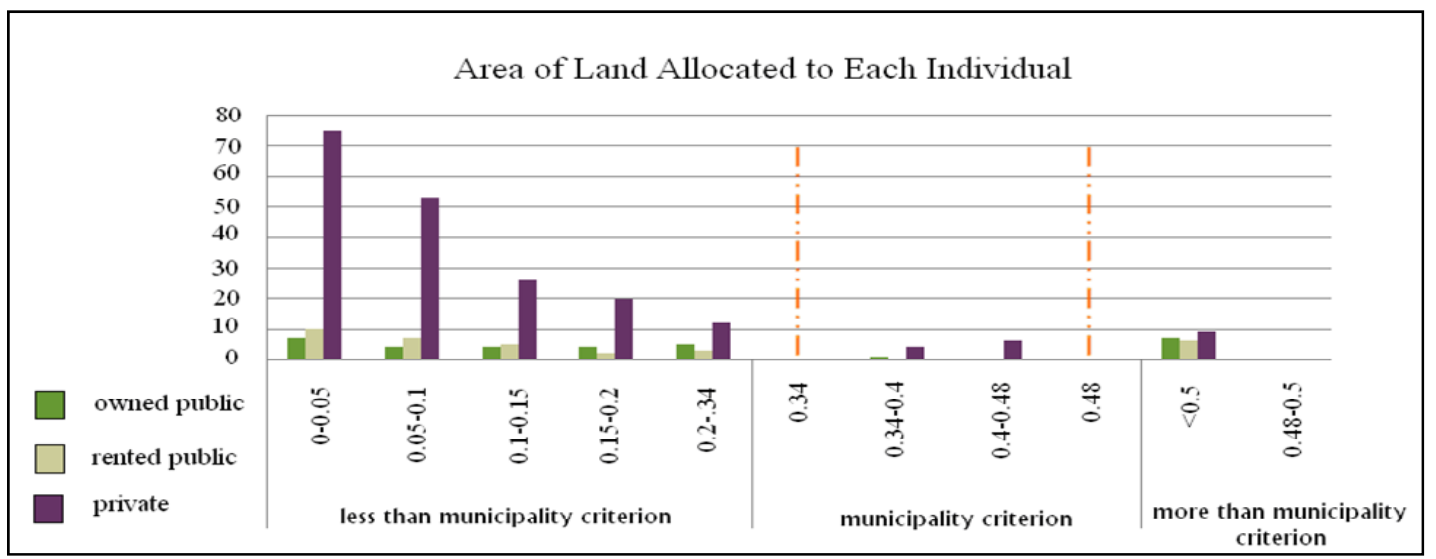

Figure 4. Primary care centers (clinics)/land area allocated to each individual of the population (standard secretariat 0.34 to $0.48 \mathrm{~m}^{2} /$ individual)

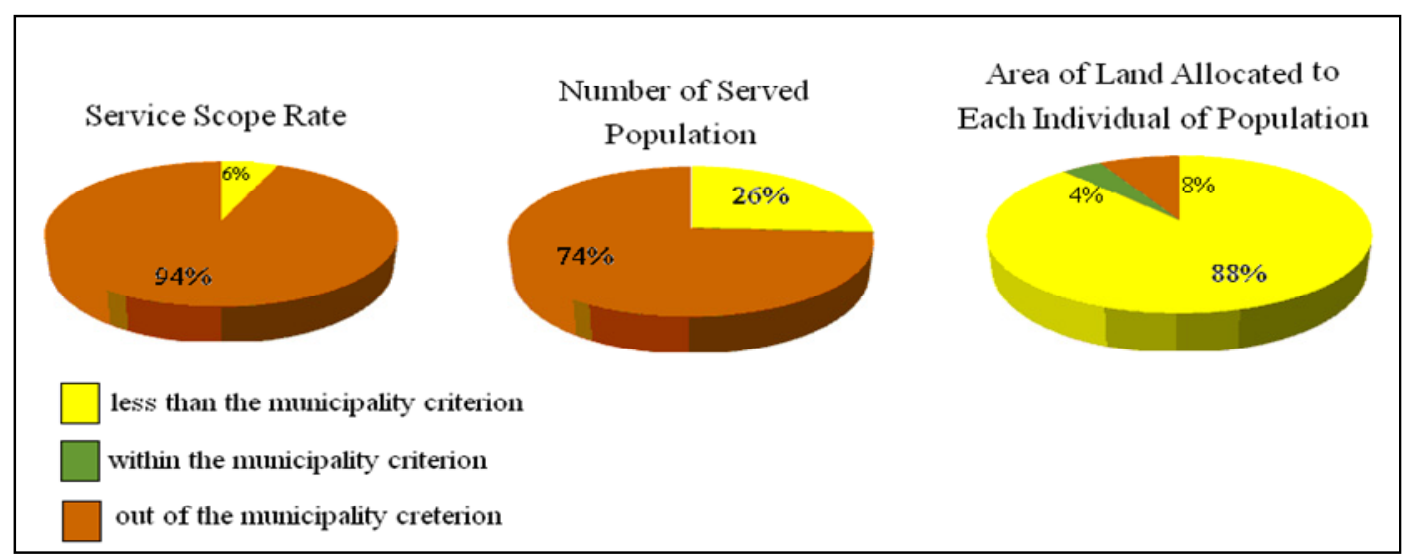

Figure 5. Comparison of analysis for results of primary health care centers reality with the criteria approved by the Municipality of Riyadh

(B) Hospitals

These results show the following:

- The criterion of service scope rate for the Municipality is implied moderately where half of the hospitals or equivalents to $54 \%$ have much broader service scope than criterion approved by the Municipality (3000-5000 m). 
- The criterion of served population is applied well where $28 \%$ of the hospitals serving more numbers of population than what approved by the Municipality (hospital per 8,000 individual).

- It should be noted that the allocated area per capita of population regarding hospitals was not included in this section of the report because of the lack of data related to the services planning criteria in the Municipality.

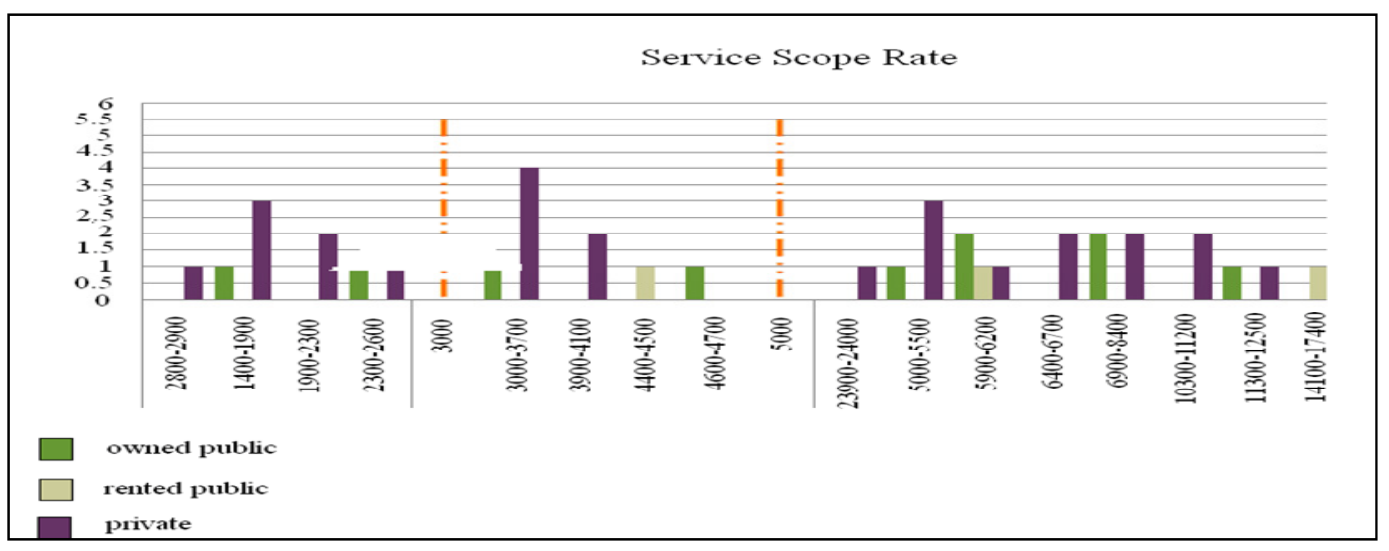

Figure 6. Hospitals / service coverage rate (Municipality criterion: 3000-5000 m)

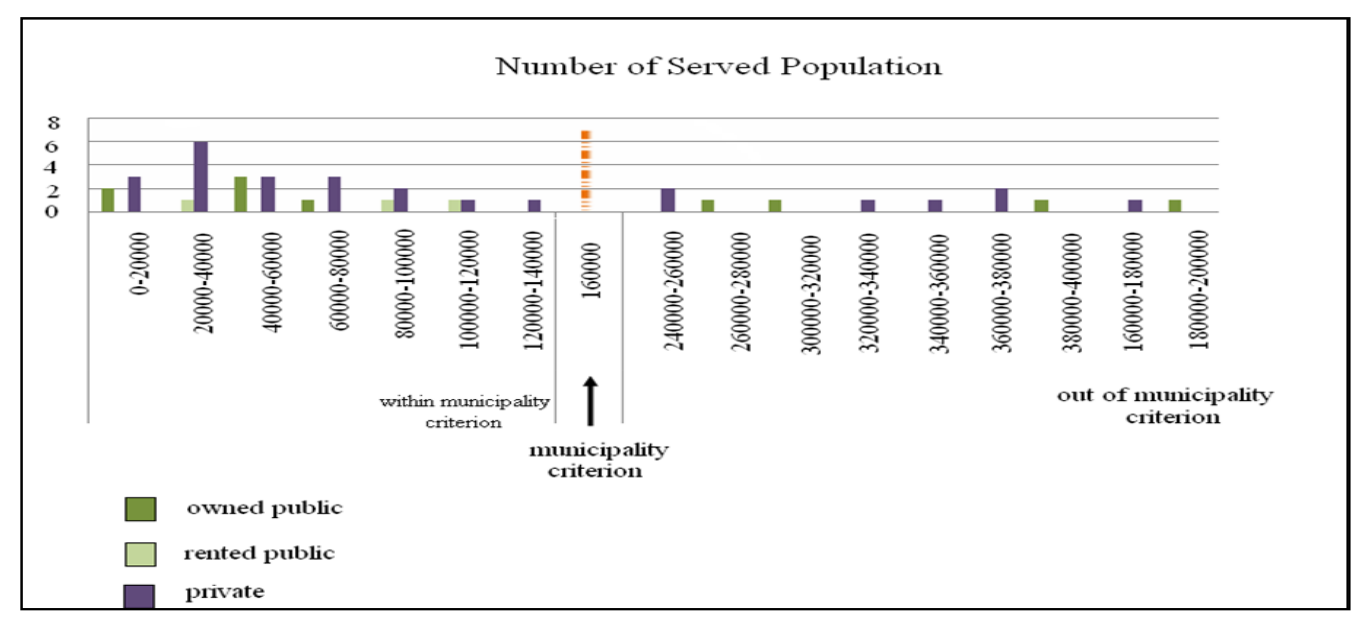

Figure 7. Hospitals / number of served population (Municipality criterion: Hospital per 8,000 individual)

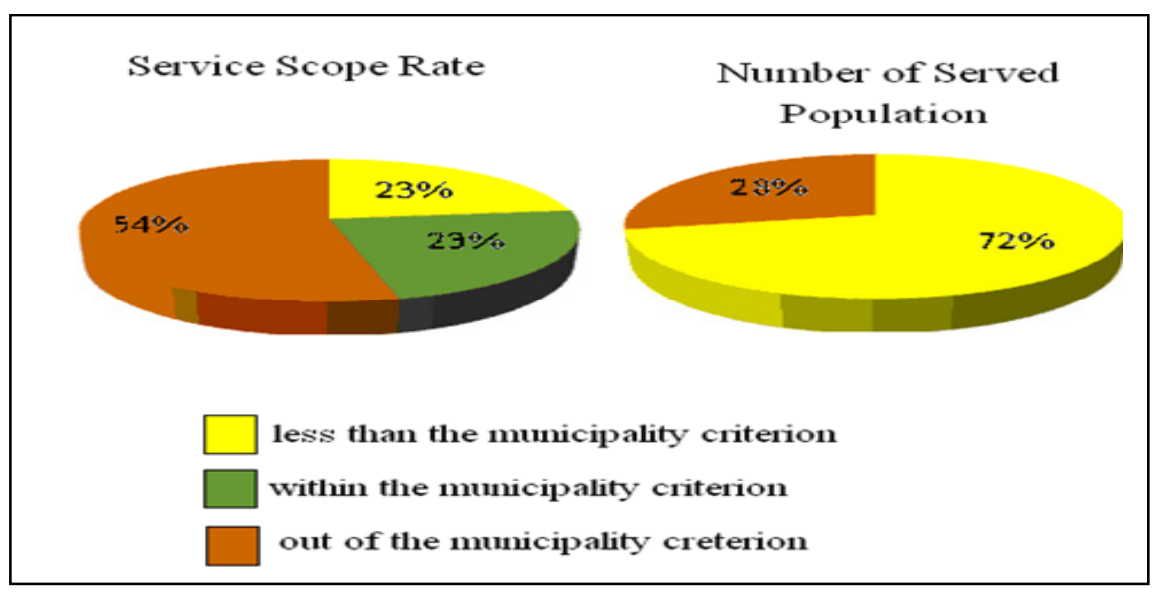

Figure 8. Comparison of analysis for results of hospitals reality with the criteria approved by the Municipality Riyadh 


\section{Comparison of Current Criteria with the Planning Criteria in Other Cities}

The comparison of global and local planning criteria and experiences of other countries calls attention that some of these planning criteria are different from the Saudi society in terms of environment, climate, developmental policies and the social customs (Hartigan, 1975). Therefore, the comparison of these criteria must be based on countries with similar living conditions and taking into account the privacy of citizens in the city of Riyadh such as:

- The form of the city and its geographical location.

- The social structure of the city.

- The economic situation.

- The environment and nature.

- Development of structure of urban growth.

The planning criteria applied by the municipality of Riyadh were compared with a number of Arab and international cities such as Jeddah, Mecca, Dubai, Muscat, Manama, Kuwait, Kuala Lumpur. Moreover, modern international cities such as Rincon and Fairfax in Britain and America as developed countries were addressed. Furthermore, considering the most prominent issues related to those criteria (the degree of complying with sectorial policies, congruity with the nature and climate of the city of Riyadh). The following represent a comparison of service criteria under consideration with local and international criteria:

\section{A) Preliminary care centers/clinics}

Graphs show the extent of compatibility for the criteria applied in the Municipality of Riyadh with local and international criteria. It was found that the number of served population was less than the rate implemented in most other cities. Also the comparison of service coverage rate was unavailing since this criterion is not taken into account in the other cities. Furthermore, the allocated land area per capita was high compared with the other cities.

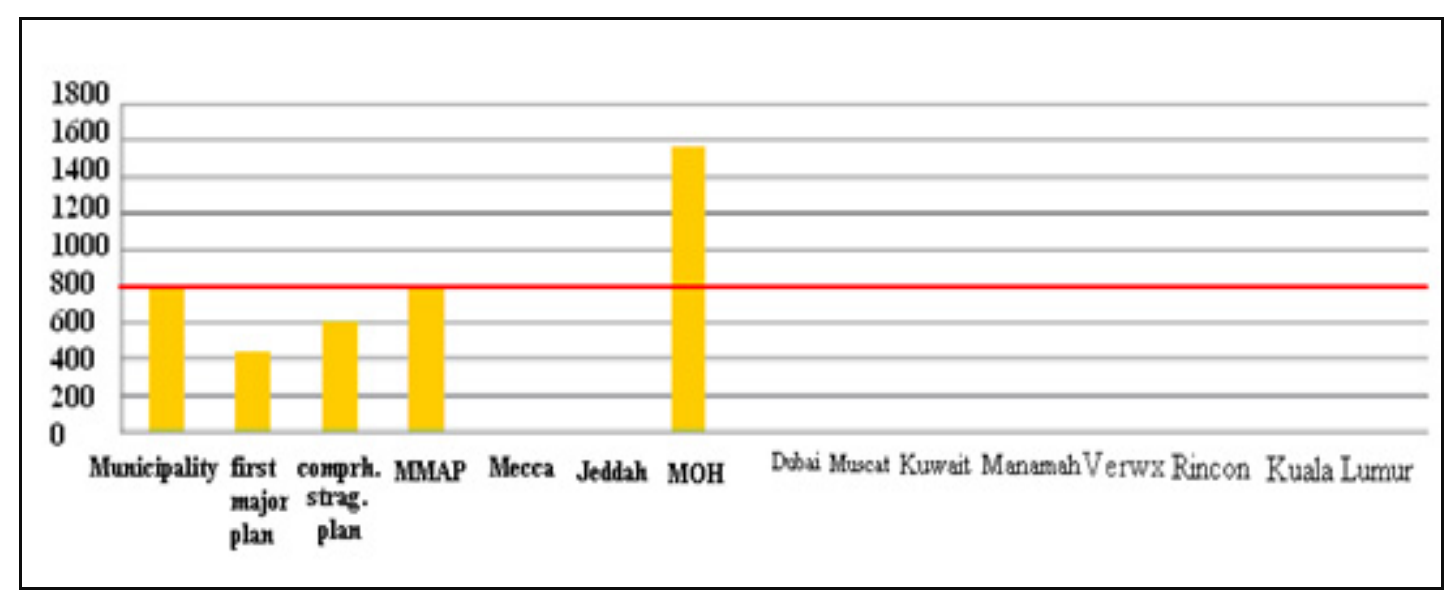

Figure 9. Evaluation of standard Riyadh Municipality (2000): preliminary care centers/clinics versus service scope rate (in meter) 


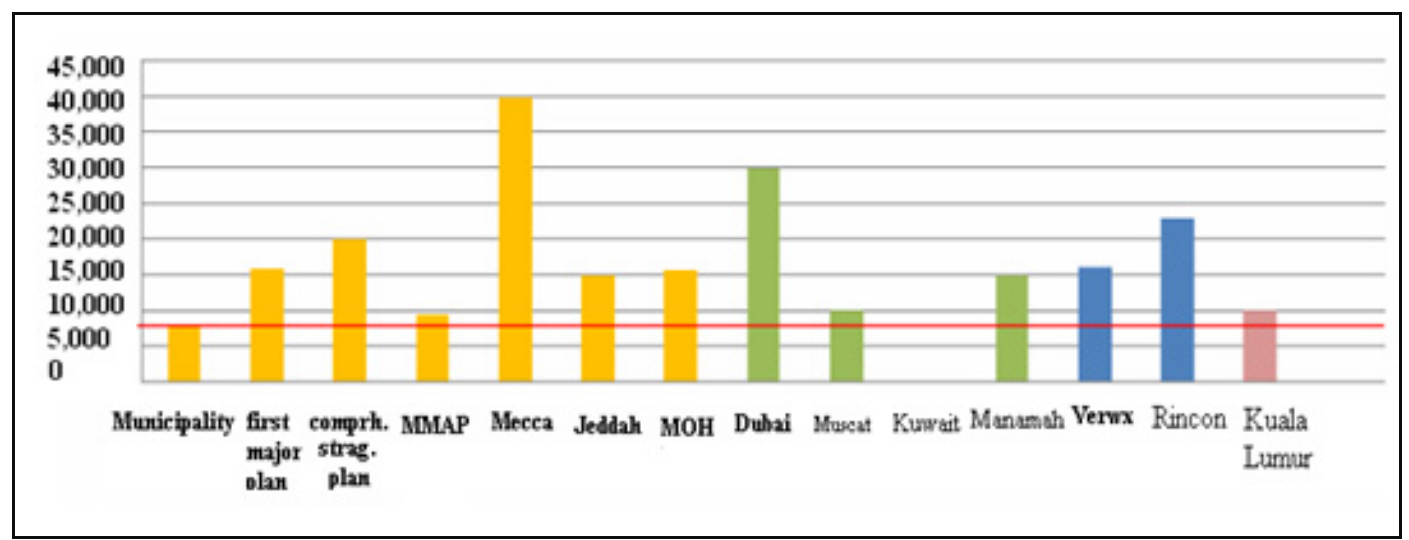

Figure 10. Evaluation of criterion for the Municipality of Riyadh: Preliminary care centers/clinics versus the number of population served in the area (per capita)

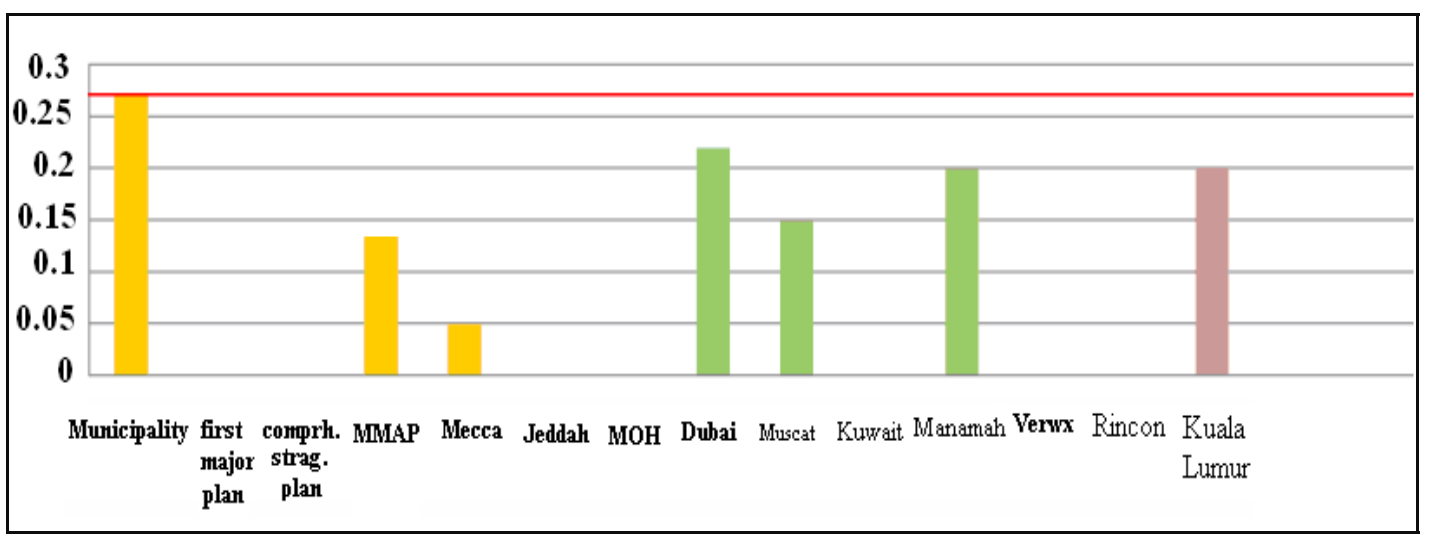

Figure 11. Evaluation of criterion for the Municipality of Riyadh: Primary health care centers/clinics versus the area of service land $\left(\mathrm{m}^{2} /\right.$ individual $)$

\section{B) Hospitals}

Graphs show the extent of compatibility for the criteria applied in the Municipality of Riyadh with local and international criteria. It was found that the criterion of served population is asymptotic to the served population in Dubai. In addition, most cities do not adopt the criterion of service coverage rate and that the area allocated per capita was higher than the allocated area in the other cities that have been considered. Thus the criterion of land's area allocated to each individual is relatively high compared with other cities.

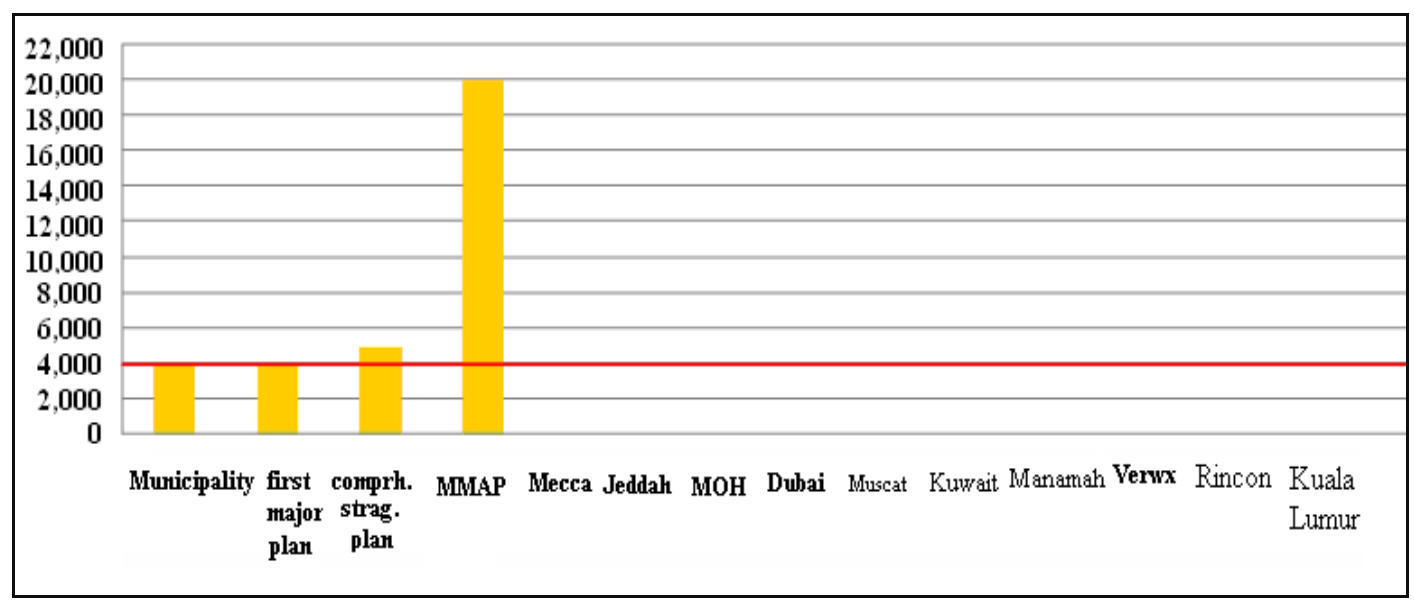

Figure 12. Evaluation of criterion for the Municipality of Riyadh: hospitals versus service scope rate (in meter) 


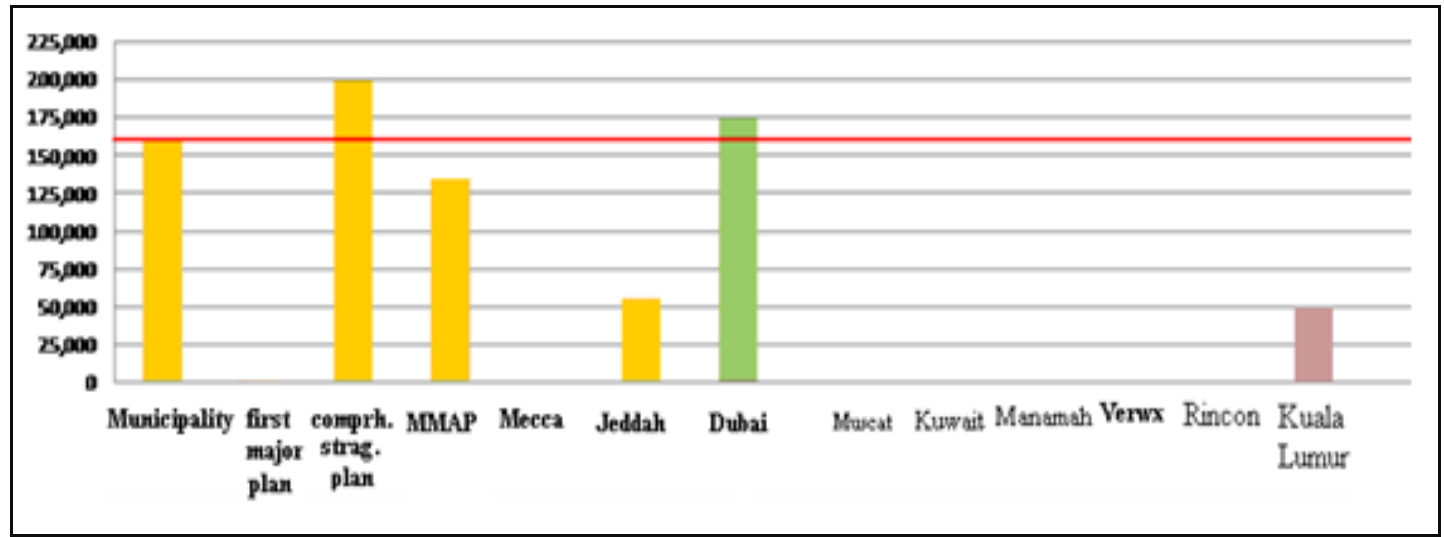

Figure 13. Evaluation of criterion for the Municipality of Riyadh: hospitals versus the served population (per capita)

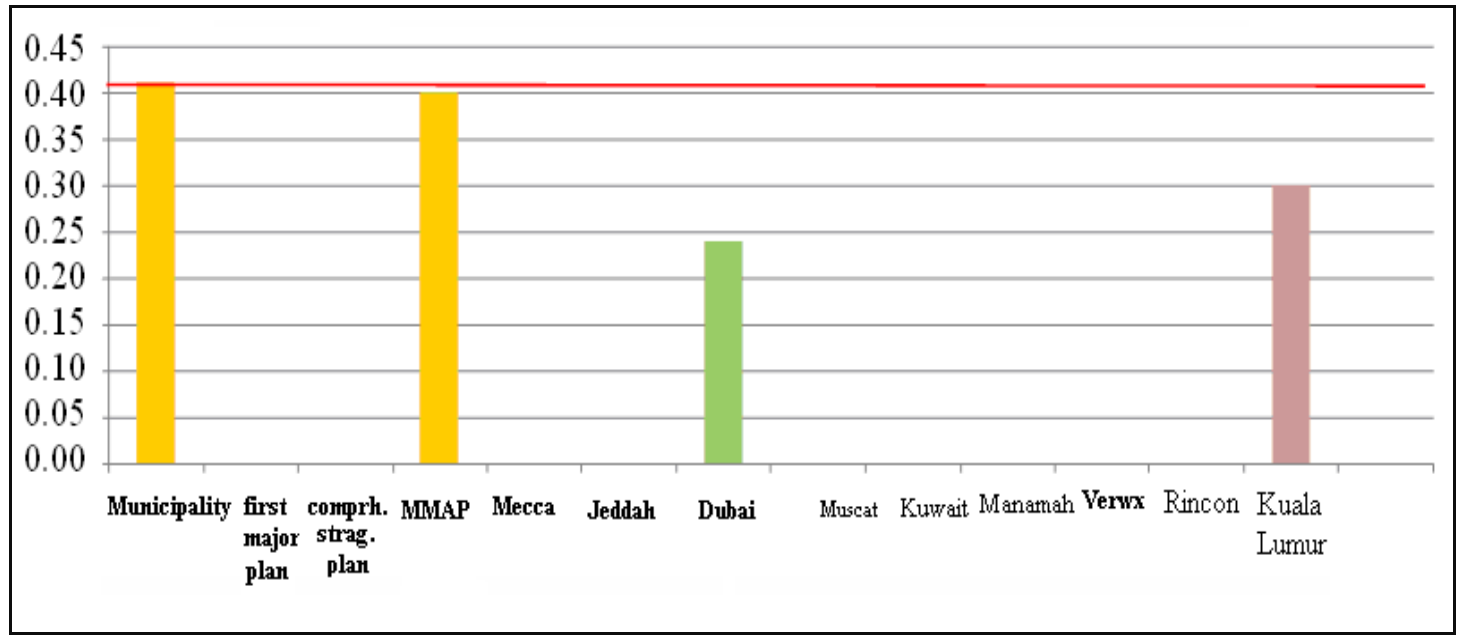

Figure 14. Evaluation of criterion for the Municipality of Riyadh: hospitals versus the area of service land $\left(\mathrm{m}^{2} /\right.$ individual)

\section{The Proposed Criteria for Health Services}

The revised criteria regarding health services were reviewed. Based on the results obtained from reviewing planning criteria in Arab and international cities, the nature of the urban and social fabric in the city of Riyadh, in addition to what has been deduced from the extent of compatibility of current criteria with the practical reality of health services, a planning criteria was proposed for health services (Taylor \& Kuljis, 1998).

The problem of health services was related to implementing the criteria of planning and not to their levels since reviewing and comparing the current status for these services with the criteria of Municipality indicated that the vast majority of clinics and hospitals have broader coverage of service than the criterion of Municipality with serving much more numbers of population than what approved in the criterion of Municipality. They also afford square meters per capita less than the criterion of Municipality. It is therefore proposed to maintain the same criteria with proposing adoption of the minimum limit of criteria for land area needed per person, since the areas of required lands for the clinics are limited areas and should be available within the range of service required even if requires carrying out the expropriation or diversion of government land usage. The explanation is represented in the following:

A) Primary health care centers / clinics

During the selection of the health center site, it should be taken into account the site which mediates the neighborhood and located by major or aggregated roads. 
Table 4. The existing and proposed criteria of primary health care centers

\begin{tabular}{ccc}
\hline Preliminary care centers & The current criterion of Municipality & Proposed criterion \\
\hline Service scope rate (in meter) & 800 & 800 \\
Number of served population & 8000 & 8,000 \\
Area allocated per individual $\mathrm{m}^{2}$ & $0.48-0.34$ & 0.25 \\
\hline
\end{tabular}

\section{B) Hospitals}

Public hospitals: it is preferable for the sites of public hospitals to be near the main roads away from the factories, sports stadiums, markets and workshops as well as it is necessary to choose the hospital entrance on a service road so that emergency entrances located on roads do not suffer from congestion or heavy traffic. Also it is necessary to take into account the area of the site to be sufficient to create green spaces and the different coordinating elements for the site that allows patients to exercise light sports.

Specialized hospitals: it has the same considerations of public hospitals except that specialized hospitals with infectious diseases should be located on a distance not less than $500 \mathrm{~m}$ from the surrounding residential areas. It is advisable to be isolated and use plants inside and on the sides especially high trees.

The comparison with the quality indicators of service indicates that the number of beds in hospitals is determined in accordance with the benchmark criterion of 4 beds / 1000 individual. Specialists consider that each bed needs $150 \mathrm{~m}^{2}$ of built-up area. Since the good and sustainable design of buildings requires the use of a limited part of the ground with avoiding the use of the site horizontally. Also to adopt investment factor ranges between 3 and 5 which means the need for 30 to $50 \mathrm{~m}^{2}$ per one bed. In addition to surface areas for parking on the basis of a car or two cars per one bed, so that the total area will reach to $80-100 \mathrm{~m}^{2}$ per bed for a between 0.32 and $0.4 \mathrm{~m}^{2}$ as shown in Table (5).

Table 5. The existing and proposed criteria of hospitals

\begin{tabular}{ccc}
\hline Hospitals & The current criterion of Municipality & Proposed criterion \\
\hline Service scope rate ( in meter) & $3,000-5,000$ & 4,000 \\
Number of served population & 16,000 & 16,000 \\
Area allocated per individual $\mathrm{m}^{2}$ & $3,000-5,000$ & 0.4 \\
\hline
\end{tabular}

\section{Conclusion}

Due to the scarcity of lands and the difficulty of its provision, in addition to the application of proposed planning criteria, it is recommended to apply specific techniques and means as follows:

- $\quad$ Regarding high-density neighborhoods where there are no public lands it is necessary to carry out the expropriation within the neighborhood, which is the only solution, sponsored to apply the criterion of health service coverage.

- $\quad$ Regarding low-density neighborhoods where there is an adequate government land or it is easy to carry out the expropriation, applying the proposed criteria of health services is possible.

- Achieving the principles related to economies of scale that is reducing in the cost of construction by collecting service units in a common center.

- Increasing the number of served individuals in the Primary care centers / clinics and reducing the land area for each individual so that they can provide a greater number of services using less space.

- $\quad$ Adopting of service coverage (in meter) for served individuals in hospitals and reducing the land area allocated to each individual to facilitate the provision of land and reduce the deficit in hospitals. 


\section{References}

Bandura, R. (2006). A Survey of Composite Indices Measuring Country Performance: 2006 Update, United Nations Development Programme - Office of Development Studies. Retrieved from: http://www.thenewpublicfinance.org/background/Measuring\%20country\%20performance_nov2006\%20up date.pdf

Charnes, A., Cooper, W. W., Lewin, A. Y., \& Seiford, L. M. (1995). Data Envelopment Analysis: Theory, Methodology and Applications. Boston: Kluwer.

Ebert, U., \& Welsch, H. (2004). Meaningful environmental indices: a social choice approach. Journal of Environmental Economics and Management, 47, 270-283.

Hartigan, J. A. (1975). Clustering Algorithms. New York: John Wiley \& Sons, Inc.

Ministry of Health. (1994-200). The annual health report. Riyadh: Ministry of Health.

Ministry of Health. (1999). The explanatory note for the current health situation and the health system proposed to provide health care. Riyadh: Ministry of Health.

Ministry of Health. (2001). Healthy development in the era of King Fahd. Riyadh: Ministry of Health.

Ministry of Health. (2007). Standards of Ministry of Health: the guiding planning criteria for Health Services. Riyadh: Ministry of Health.

Ministry of Municipal and rural Affairs. (2000). Controls and the planning standards. Riyadh: Ministry of Municipal Affairs and projects.

Ministry of Planning. (2004). The Seventh Development Plan (2000-2004). Riyadh: Ministry of Planning.

Ministry of Municipalities and Rural affairs. (2001).

OECD. (2008). Handbook on Constructing Composite Indicators: Methodology And User Guide. France: OECD.

Office of National Statistics. (2005). National Population Forecasts, Office of National Statistics. Retrieved from http://www.statistics.gov.uk/themes/population/default.asp

Taylor, S., \& Kuljis, J. (1998). Simulation in health care management: modelling an outpatient clinic. OR Insight, $11,7-11$.

www.nationmaster.com/cat/hea-health

www.nationmaster.com/graph/hea_hos_bed_Per_1000_peo-beds

www.nationmaster.com/graph/hea_hos_bed-health-hospital-beds

www.nationmaster.com/graph/hea_phy_per_1000_peo-physician-per-1-000-people

\section{Notes}

Note 1. Occupancy rate: The number of patients attending the health unit (hospital - primary care center / clinic) during the week.

Note 2. The indicator of Patient/ health unit represent the number of patients per one week.

Note 3. With consideration to number of Bid/ hospital reached to 25 hospitals in case of adding 10 specialized hospitals to the public ones (15 hospitals) listed in previous table. 